\title{
FEMINISMO EN TEMISCIRA: LAS FACETAS DE WONDER WOMAN $^{1}$
}

\author{
Marcos Rafael Cañas Pelayo
}

\section{Feminismo en Temiscira: Las facetas de Wonder Woman}

Resumen: A pesar de ser el personaje femenino más popular del cómic superheroico, la historia de Wonder Woman está llena de avances y retrocesos: concebida por su creador, el célebre psicólogo William Moulton Marston, como un símbolo de la mujer librepensadora, emancipada, pacifista y sufragista, también sufrió períodos de banalización y alejados de su verdadero potencial como icono feminista. La reciente película de la princesa Amazona ejemplifica las distintas dimensiones (mitológica, activista, estética, etc.) que han acompañado a este símbolo de la cultura popular, siempre en la frontera entre el estereotipo y la inspiración.

Palabras clave: feminismo, mitología clásica, movimiento sufragista, emancipación y cómic.

\section{English Title: Feminism in Themyscira: Wonder Woman's Facets}

Abstract: Despite being the all-time most popular female character of the superhero comic genre, the history of Wonder Woman is full of advances and setbacks: conceived by the famous psychologist William Moulton Marston as a symbol of the freethinking, emancipated, pacifist and suffragette woman, the character also suffered from some banalization, far away from her true potential as a feminist icon. The recent movie about the Amazon princess exemplifies the diverse dimensions (among others, mythological, activist or aesthetic) which have long accompanied this popular culture symbol, always on the border between stereotypes and inspiration.

Key words: feminism, classic mythology, sufragette movement, emancipation and comic book.

\section{Introducción}

El reciente estreno de la película Wonder Woman (2017), bajo la dirección de Patty Jenkins, ha supuesto el primer filme del DC Extended Universe (DCEU) ${ }^{3}$ con una superheroína como protagonista, tras el estreno de la princesa amazona en la gran

\footnotetext{
${ }^{1}$ Fecha de recepción: 22/10/2017.

Fecha de aceptación: 21/05/2018.

${ }^{2}$ Doctor Europeo por la Universidad de Córdoba; Colaborador Honorario Departamento de Historia Moderna, Contemporánea y de América Universidad de Córdoba; Profesor de Geografía e Historia en el IES San Jerónimo (Sevilla); $\bowtie$ capemarcos@ @otmail.com.

${ }^{3}$ Ficticio universo compartido de películas centradas en los personajes aparecidos en las publicaciones de DC Comics.
} 
pantalla con un papel secundario en Batman contra Superman: El amanecer de la justicia (Zack Snyder 2016).

La buena acogida que público y crítica han brindado a la encarnación de Gal Gadot como Diana de Temiscira garantiza futuras apariciones del personaje de cómic en la gran pantalla. No obstante, Wonder Woman se ha visto expuesta a distintas interpretaciones en sus más de setenta y cinco años de historia, no pocas de ellas incluso contradictorias entre sí.

Admirador de la labor llevada a cabo por Emmeline Pankhurst y el incipiente movimiento sufragista femenino, William Moulton Marston (1893-1947), creador de Wonder Woman, estaba convencido de que su heroína podría abanderar esos ideales en el universo de las viñetas (Lepore 2014: 3-12). Sin embargo, de esas tesis feministas iniciales, la princesa Diana pasaría por años alejados de esos objetivos, viendo su mensaje desvirtuado.

Afortunadamente, otros equipos creativos recuperaron ese espíritu original, además de enriquecerlo con una profundización en el legado mitológico y de cultura clásica en que anidaban las raíces de Diana. Resulta de interés observar cómo la película ha ido seleccionando de ese amplio abanico de referencias para reconfigurar nuevamente a una protagonista icónica, reconocible para las audiencias de todo el globo. 


\section{Los orígenes de un icono: poliamor y liberación}

Nacido en Saugus, Massachusetts, en 1893, en el seno de una familia de clase media, Charles Moulton Marston fue un destacado escritor, psicólogo e inventor norteamericano. Diplomado en Psicología por la universidad de Harvard, graduado en Derecho y doctorado en 1921, su prolífica carrera comenzó de la mano de Hugo Münsterberg (1863-1916), de quien aprendió el potencial de la cultura de masas como vehículo de difusión, así como un cierto carácter exhibicionista para plantear sus teorías (Sandifer 2013: 39-40).

Emotions of Normal People (Moulton Marston 1928) fue su libro de más repercusión, además de dirigir varios espectáculos psicologistas en diferentes teatros de New York, los cuales generaron bastante polémica. Posteriormente, tuvo un frustrado intento de prosperar en la industria cinematográfica ${ }^{4}$, interesándose cada vez más en la incipiente industria del cómic, convencido de que podía ser un escaparate perfecto para la plasmación de algunas de sus teorías.

Como el propio creador admitió en diferentes ocasiones, buena parte del mérito de su futura creación debía mucho a dos mujeres: Elizabeth Holloway (1893-1993) y Olivia Byrne (1904-1985). La primera era la esposa de Marston, una de las primeras mujeres norteamericanas en obtener tres titulaciones universitarias en una época en la que resultaba extraño que miembros de su sexo pudieran acceder a esos niveles de estudios superiores. Doctora en Psicología, compartía con su esposo el firme

\footnotetext{
${ }^{4}$ Durante un año estuvo al cargo de la Oficina de Servicios Públicos de la compañía Universal Pictures, si bien no logró la materialización de sus proyectos creativos en este medio.
} 
convencimiento de la necesidad de sufragio femenino y la defensa del pacifismo ${ }^{5}$. Consciente del interés de su esposo por el cómic, le recomendó que hiciese una historia sobre una superheroína.

Las posibilidades de ese concepto atraían a la pareja. Las viñetas se antojaban una oportunidad para exponer sus teorías sobre el nuevo tipo de mujer que estaba destinada a romper sus ataduras, ocupando puestos preeminentes en la vida económica y cultural de la sociedad. Ya existían precedentes de protagonistas femeninas en el medio (Nicholson 2017), pero ninguna hasta ese momento había llevado consigo ese ideario tan transgresor para la época (Greenberger 2017).

Por su lado, Olivia Byrne sería otra de las grandes inspiradoras para la apariencia definitiva de la amazona. Tras iniciar una relación estrecha con la pareja en $1925^{6}$, una de las cuestiones que más llamaron la atención a Marston fueron dos pesados brazaletes que la mujer solía llevar, procedentes de México y África, respectivamente. Byrne los empleaba como símbolos de amorosa sumisión, quizás sin ser consciente de que estaba otorgando uno de los sellos más distintivos que Gal Gadot portaría en cada batalla de la reciente película sobre la heroína.

Igual que sucede con Elizabeth Holloway, indagar en la genealogía de Olivia Byrne explica claramente la relevancia que tuvo en la gestación de Wonder Woman. Hija de la enfermera rebelde Ethel Higgins Byrne (1883-1955) y sobrina de Margaret

\footnotetext{
${ }^{5}$ Formada en el college de Mount Holyoke, Elizabeth Holloway destacó la influencia que tuvo en su ideario la figura de Mary Emma Woolley (1863-1947), una de las primeras voces favorables al control de la fertilidad, la igualdad de voto y una clara actitud contraria a cualquier clase de belicismo. Recientes estudios sobre los orígenes de Wonder Woman han subrayado el papel de Elizabeth en el proceso de creación de la heroína (McCausland 2017: 54-59). No parece causal que Safo fuera la poetisa predilecta de Elizabeth; probablemente esa fascinación por la antigua Grecia ayudó a Marston a dar ese trasfondo a su protagonista (Pujol Tost 2009: 38-49).

${ }^{6}$ Se trata de uno de los primeros casos reconocidos de poliamor. Es decir, cuando tres o más personas mantienen una relación a diferentes niveles (afectivo, sexual, etc.) con pleno consentimiento de las partes. El vínculo entre los tres se mantuvo hasta la muerte de Marston en 1947. De hecho, incluso tras su fallecimiento, Byrne y Holloway continuaron su nexo.
} 
Sanger $^{7}$ (1879), se trataba de una convencida activista por la necesidad de cambios en la sociedad norteamericana.

Nunca hasta entonces se habían combinado esos elementos en defensa de la igualdad entre sexos en un marco tan patriarcal como el de la industria del cómic en plena Edad de Oro $^{8}$. Maxwell Gaines ${ }^{9}$, quien había contratado a Marston como asistente editorial, terminó dando su aprobación al proyecto de publicar en All Star Comics la primera aventura de una superheroína diferente a las anteriores (Robbins 1997), aunque no sin antes imponer su criterio con respecto al nombre con el que sería conocida ${ }^{10}$.

\section{En los dominios de Ares}

Los Estados Unidos entraron en la II Guerra Mundial tras el ataque que sufrió la base militar de Pearl Harbor (7 de diciembre de 1941) a mano de la aviación japonesa. La entrada en este conflicto, con un peso muy destacado de los frentes del Pacífico y Europa, supondría importantes consecuencias para la sociedad norteamericana.

Debido a los masivos reclutamientos de varones a filas, cerca de cinco millones de mujeres entraron a formar parte activa de la vida laboral del país (McCausland 2017:

\footnotetext{
${ }^{7}$ Figura de capital importancia en la historia de la defensa de los derechos reproductivos. Fue una de las impulsoras y posterior presidenta de la Planned Parenthood Federation of America (PPFA), la cual terminó teniendo eco en muchos otros países (Reed 2003).

${ }^{8}$ Forma por la que popularmente se conoce a los cómics publicados en Estados Unidos en el período comprendido entre los años de 1938 y 1950. El medio al fin logra alcanzar un rango propio, evolucionando de los simples gags ilustrados de las tiras de prensa hasta alcanzar una voz narrativa propia.

${ }^{9}$ Junto con Jack S. Liebowitz, Gaines fundó diferentes cabeceras editoriales para entretenimiento, bajo el título de All American Publications. Cuando este grupo se fusione con Detective Comics y National Allied Publications, se producirá el germen de la futura National Comics Publications (1946), inmediato antecedente de la futura DC.

${ }^{10}$ Marston iba a llamarla inicialmente Suprema, si bien terminó renunciando a esa idea para evitar comparaciones con personaje recién creado, Superman. Estimó que Wonder Woman le daría más independencia y alejaría la posibilidad de que el público pensase que era una mera contrapartida femenina del célebre héroe con la $\mathrm{S}$ en el uniforme.
} 
25). Esta transformación permitió el acceso de muchas de ellas a esferas que les habían sido vetadas hasta hacía muy poco. Quedaba un largo camino por recorrer, especialmente en materia de la discriminación sexual de salarios, si bien era un punto de inflexión que ayudaría al incipiente movimiento feminista que estaba surgiendo (Lepore 2014: 13-23).

Paralelamente, la industria del entretenimiento también abrazaba con agrado los ideales patrióticos y la más directa propaganda con el fin de fomentar un espíritu opositor a las fuerzas del Eje. No en vano, apenas unos meses antes del primer número de Wonder Woman, Joe Simon y Jack Kirby dibujaban la célebre portada del Capitán América propinando un puñetazo al mismísimo Adolf Hitler (Rodríguez 2013: 41).

Con la única excepción del cine, estas aventuras ilustradas eran la mejor herramienta de propaganda que existía para transportar al gran público a misiones de espías y hazañas bélicas. Es ese contexto de la II Guerra Mundial el que nos permite comprender el debut de Wonder Woman en las páginas de All-Star Comics \#8 USA ${ }^{11}$.

El marco del relato comienza con el intento de huida de Steve Trevor, oficial de inteligencia de los Estados Unidos, de una persecución de pilotos nazis que han descubierto su papel de agente encubierto. En algún punto del Triángulo de las Bermudas, el avión de Trevor se estrella en la Isla Paraíso ${ }^{12}$, donde es recogido por una tribu de amazonas que ha alcanzado una gran prosperidad como civilización, ocultas al mundo de los seres humanos.

\footnotetext{
11 Publicado en diciembre de 1941. Poco tiempo después, se descubriría que la heroína tenía una identidad civil secreta, Diana Prince (Sensation Comics \#1 USA, enero de 1942). La incipiente popularidad alcanzada por la amazona le valió una cabecera con su nombre en junio de ese mismo año.

${ }^{12}$ No sería hasta la década de los 80 del pasado siglo cuando al fin se dio el nombre de Temiscira a la capital de las amazonas. Según el argumento de Marston, gracias a la magia de los dioses olímpicos, el enclave pudo permanecer sin ser cartografiado o descubierto por ojos indiscretos.
} 
Tras ser interrogado por su reina, de nombre Hipólita, Trevor consigue convencer a las guerreras de la justicia de su causa. Incluso la diosa Palas Atenea intercede a favor del norteamericano, sellándose un pacto que hará que la mejor de su tribu acompañe al piloto sano y salvo a su hogar. La vencedora de las competiciones para dirimir ese puesto, bajo el título honorífico de Wonder Woman, resulta ser la propia hija de la líder, de nombre Diana.

Harry George Peter sería el veterano dibujante elegido por Marston para el diseño gráfico de la princesa amazona. Dicho ilustrador tenía experiencia trabajando en revistas y magacines, habiendo además compartido estudio con algunos de los más destacados artistas de la propaganda de la I Guerra Mundial ${ }^{13}$. El uniforme de Diana como Wonder Woman sería el resultado de una larga discusión.

Olivia Byrne fue la modelo en la que se inspiró Peter para los rasgos físicos de la heroína. De hecho, como hemos mencionado con anterioridad, sus brazaletes plateados serían trasladados a las viñetas como símbolo de amorosa sumisión ${ }^{14}$. Hay varios guiños a la cultura norteamericana en su indumentaria: entre otros, una falda con cincuenta estrellas, alegoría de los estados del país (McCausland 2017: 50), con un predominio de colores de su bandera: rojo, blanco y azul.

Buscando un tono más universal y no ceñido a una sola nación, Michael Wilkinson diseñó el vestuario para la reciente película, donde la apuesta opta

${ }^{13}$ Destaca en ese sentido su vinculación con James Montgomery Flagg, uno de los principales responsables de la icónica imagen del tío Sam y Columbia, la personificación femenina de ese mismo ideal. La popularidad de la segunda la llevó a ser el logo oficial de Columbia Pictures. El padre del ilustrador, Henry George, había sido el dueño de un periódico claramente favorable al sufragio femenino. Asimismo, Peter tuvo una estrecha relación con Lou Rogers, una de las primeras dibujantes de animación. ${ }^{14}$ Diferentes teorías afirman que este elemento es un claro guiño al bondage, es decir, una práctica erótica que juega con la fantasía de la dominación. A diferencia de muchos otros cómics de la época, hay una provocadora y adelantada sexualidad en los primeros números de Wonder Woman (Mitchell Peters 2003: $1-9)$. 
claramente por un eclecticismo entre el helenismo clásico y el mito amazónico. Si en su primera portada Wonder Woman aparecía escoltada por el Capitolio de Washington y el edificio de la Corte Suprema, el filme buscará alejarse de esa adscripción a un solo país.

De hecho, la dirección de Patty Jenkins pretende en su adaptación acercarse al verdadero punto de arranque de las teorías de Marston: la labor de las primeras sufragistas británicas. En su versión, Trevor trabajaría para los intereses de Gran Bretaña $^{15}$, siendo acompañado por Diana para luchar por la paz en Europa; eso sí, la película adelanta los acontecimientos para que su toma de contacto con el mundo del ser humano sea la I Guerra Mundial.

El original planteamiento de Marston permitía usar el género superheroico para plantear los problemas de la discriminación sexual (Robinson 2004), si bien el clima geopolítico de su gestación obliga a releer esos números con una adecuada contextualización. Jenkins y su equipo logran traer a una Dana de Temiscira más crítica con el mundo de sus aliados, pues observa el escaso aprecio y reconocimiento que se da a las mujeres, incluso en una ciudad cosmopolita y próspera como Londres ${ }^{16}$.

Tras varias discusiones entre los creadores, se determinó quitar a Diana las sandalias de los primeros bocetos de la heroína, cambiándolas por unas botas. Asimismo, Marston le introdujo una de sus armas más célebres: el lazo de Gea, el cual

\footnotetext{
${ }^{15}$ Parece claro el intento de adaptar una estética en esas escenas que hermane a la cinta con Sufragistas (Sarah Gavron, 2015), ambientada entre los años de 1910 y 1919, poniendo un especial acento en las feministas surgidas de la clase obrera. El conflicto bélico coincidió con la gran eclosión del movimiento. Similar circunstancia se da en los Estados Unidos, donde la administración del presidente Woodrow Wilson se verá forzada por las circunstancias a conceder el voto a las mujeres norteamericanas en 1920, tras las activas protestas que se dieron durante el período del conflicto (Unwin 2008).

${ }^{16} \mathrm{La}$ Gran Guerra permite asimismo a la película de Wonder Woman mostrar la locura y sinsentido de la lucha. Mientras Marston hace que Hipólita y sus amazonas abracen la causa estadounidense sin un atisbo de duda, aquí se mostrarán convencidas de que la irracional contienda es fruto de una confabulación de Ares, una de las deidades más poderosas del Olimpo. En diferentes etapas de la colección, el dios de la guerra ejercerá el papel de gran Némesis de la heroína y los valores de convivencia que pregona Isla Paraíso.
} 
permitiría a la amazona descubrir si la persona alrededor de él mentía o era sincera (Langley y Wood 2017). Fascinado por los primeros polígrafos, el psicólogo quiso otorgar esa facultad a su protagonista (Lepore 2014: 36-38).

\section{Transgresión y retroceso}

Las ventas durante los primeros años garantizaron la popularidad de Wonder Woman ${ }^{17}$. Sus autores conseguirían introducir varias críticas al machismo imperante que podía encontrarse incluso en las organizaciones criminales, a través de un curioso personaje, el Doctor Poison. En realidad, tras la máscara del villano se escondía una ambiciosa e inteligente mujer, la princesa Maru, la cual es perfectamente consciente de que ninguno de sus esbirros aceptaría acatar sus órdenes de conocer su verdadero sexo.

El poso que ha dejado esa enemiga en el panteón de adversarias de la amazona ha permitido que una versión de Maru apareciera en la adaptación a la gran pantalla, interpretada por la actriz Elena Anaya ${ }^{18}$. La doctora desempeña un papel importante en el metraje como la principal responsable de fabricación de armas químicas para el ejército de Ludendorff, líder de la facción de generales la Triple Alianza que se niegan a una salida pacífica de la lucha ${ }^{19}$; el argumento otorga a Maru algunas características de otra enemiga de la Edad de Oro, la Baronesa Paula von Gunther, otro interesante

\footnotetext{
${ }^{17}$ En 1945, Marston llegó a afirmar que cifraba en dos millones y medio de personas el potencial de lectores/as que tenía su creación (McCausland 2017: 25).

${ }^{18}$ Igual que en las aventuras firmadas por Marston, Maru se vería sorprendida por la piedad de las amazonas. Si en los cómics originales era la reina Hipólita quien la acogía tras su caída e incluso la ayudaba a reconstruir su maltrecho rostro, en la película dirigida por Patty Jenkins se producirá otro acto de clemencia con la doctora derrotada, en este caso a cargo de la propia Diana (McCausland 2017: 2930).

${ }^{19}$ Caracterizado por Danny Huston. Según las pesquisas de Steve Trevor, Ludendorff y Maru podrían desequilibrar completamente la contienda con armas químicas de tremendo poder. Si bien Diana se muestra convencida de que deben hallarse bajo el influjo de Ares, terminará aceptando combatirles.
} 
ejercicio de Marston, puesto que era una antagonista que no solamente era una amenaza en el plano físico, sino que era capaz de orquestar astutos planes para afectar la economía de los países aliados, lo cual lleva a cabo en el número 7 de Sensation Comics $^{20}$.

No resulta extraño que Marston y Peter encontrasen en los enemigos un gran campo para hacer denuncia social. Una de las más llamativas sería Cheetah, identidad secreta de la joven Priscilla Rich, una joven que se esfuerza al máximo para entrar en la alta sociedad de Washington, incluso a costa de pasarse horas ante el espejo para maquillarse de forma compulsiva. Sus frustraciones la harán desarrollar otra personalidad salvaje ${ }^{21}$, la cual terminará convirtiéndose en una de las oponentes más recurrentes de Wonder Woman.

Dentro de esa galería, el doctor Psycho serviría como el principal alegato contra el maltrato machista. Influenciado en su diseño por películas como El doctor Mabuse (Fritz Lang, 1922) o El gabinete del doctor Caligari (Robert Wiene, 1920), Psycho es el disfraz de Edgar Cizko, quien vuelca su ira especialmente sobre las mujeres. Como él mismo admite, su deseo no solamente es la tortura física sino la anulación de su autoestima, en la senda de un sometimiento total (Lepore 2014: 26).

Uno de los añadidos más interesantes que la colección llevaría mes tras mes a los quioscos durante la Edad de Oro sería The Wonder Women of History, un pequeño repaso a algunas de las mujeres más destacadas en la Historia. Alicia Marble (19131990) fue la encargada de realizar esta publicación, la cual por primera vez puso el foco

\footnotetext{
${ }^{20} \mathrm{Su}$ primera aparición se remontaría a abril de 1942.

${ }^{21}$ Una idea que también estaba presente en otros medios artísticos. Por ejemplo, en el cine de la época se mostraba esa dualidad docilidad/vida salvaje de la en La mujer pantera (Tourneur, 1942).
} 
para el público juvenil en nombres como Sojourner Truth (1797-1893) o Amelia Earhart (1897-1937), entre muchas otras (McCausland 2017: 37).

Por ende, la publicación añadía una labor didáctica que resultaba excepcional en aquellos años. No obstante, dicha sección sería reemplazada en 1953 por Marriage à La Mode, la cual repasaría los diferentes rituales de matrimonio en todo el globo (McCausland 2017: 75). Marble abandonó sus funciones, mientras se marcaba un claro cambio en la política editorial con respecto a su superheroína ${ }^{22}$.

¿Qué podía explicar semejantes cambios? Hemos de considerar una serie de factores para entender las modificaciones que sufriría el universo de valores de Wonder Woman en particular, así como el cómic estadounidense en general. En primer lugar, el éxito alcanzado por el libro La seducción de los inocentes ${ }^{23}$ provocó un estado de alarma social, convenciendo a muchos lectores/as de los peligros de esta industria del entretenimiento y su capacidad para corromper a las personas jóvenes.

Se produjo una paulatina suavización de los contenidos a tratar a partir de la década de los 50 del pasado siglo. Los héroes y heroínas solitarias recibieron

\footnotetext{
${ }^{22}$ Uno de los giros más notables fue la relación de Trevor y Diana. Unidos por una mutua admiración, la pareja no parecía priorizar el matrimonio en las aventuras escritas por Marston, con varias negativas de Wonder Woman debido a la tarea que se había marcado de llevar los ideales de Isla Paraíso al resto del mundo. Las siguientes décadas mostrarían a una protagonista mucho más preocupada por pasar por el altar, siendo curiosamente Trevor quien se mantendría reticente al respecto. Ello equiparaba el personaje a las primeras versiones de Lois Lane, la célebre novia de Superman, la cual tardaría también en encontrar su autonomía e importancia en el universo DC (Hanley 2016), en un curioso paralelismo entre ambas (Hanley 2014).

${ }^{23}$ Publicado en 1945 por el doctor Fredric Wertham, psiquiatra convencido de los riesgos de los medios de comunicación de masas. El propio Congreso de los Estados Unidos defendió la necesidad de iniciar un control censor sobre la industria, siendo el germen del futuro Comics Code. Durante décadas, las compañías se veían obligadas a lograr la aprobación de este instrumento de control para poder lograr circular en el mercado con garantías de éxito. Las intromisiones de este organismo son el reflejo de distintas fases de represión. Por ejemplo, durante la caza de brujas del senador McCarthy contra los simpatizantes del comunismo (1950-1956), el Code vigiló severamente el contenido político de las publicaciones. De igual manera, cualquier mención a temas como las drogas o la lucha por los derechos civiles fueron tabú.
} 
inesperados miembros de familia, algunos incluso figuras rejuvenecidas de sí mismos, quedando aparcadas las temáticas de índole social, político y sexual (Douglas 1994).

La supervisión "moral” que sufrieron personajes como Batman o Superman fue notable; de cualquier modo, sería Wonder Woman una de las más perjudicadas. Ya antes de las reformas del Comics Code, Marston denunciaba el maltrato que recibía su creación cuando aparecía en otras colecciones. Así, Diana era miembro de la Sociedad de la Justicia ${ }^{24}$, aunque sin derecho a voto en las asambleas de los héroes (Monje 2017: 41). Lo realmente preocupante era que, en esas apariciones, la amazona, lejos de su equipo creativo habitual, aceptaba de buen grado aquellos desplantes de sus colegas masculinos.

Aquejado de cáncer, los últimos años de Marston en la colección exigieron la colaboración de Joye Hummel, la cual se antojaba como la sustituta ideal al frente de Wonder Woman cuando el creador falleció en 1947. No solamente fue denegada esa posibilidad, sino que tanto Hummel como Holloway y Byrne se vieron alejadas de cualquier tipo de control sobre la serie (McCausland 2017: 80).

Los siguientes años (1948-1958) vendrían marcados por el guionista Robert Kanigher, solvente escritor de la editorial, pero cuyo conocimiento de Diana no alcanzaba los niveles de profundidad e ideario feminista y de libertad sexual de Marston (Sandifer 2013: 74-83). De ser un personaje con características únicas, Diana pasaría a

\footnotetext{
${ }^{24}$ Creada por Gardner Fox y Sheldon Mayer, la Sociedad de la Justicia de América es la primera agrupación de héroes y heroínas del cómic. En All Star Comics \#13 USA (octubre de 1942) se producía la aceptación de Wonder Woman de formar parte de las asambleas como secretaria, sin derecho a voto en las deliberaciones. La película de Diana de 2017 se permite un curioso guiño a ese pasado, cuando observa cómo despóticos jefes del ejército británico minusvaloran y atosigan con trabajo de intendencia a sus empleadas sin considerar sus derechos. En boca de la protagonista: "De donde yo provengo, a eso se le llama esclavitud".
} 
estar supeditada a modas ${ }^{25}$ e incluso por un breve período de tiempo llegó a renunciar a sus poderes.

\section{Renacimiento}

Retirada de los primeros focos de la industria del cómic, uno de los motivos que explica el mantenimiento de Wonder Woman en el imaginario popular fue la serie de televisión protagonizada por Lynda Carter $^{26}$, la cual logró exportar su imagen al resto del globo. Pese a la popularidad del programa, hubo un punto de inflexión anterior que permitió recordar el propósito original de la heroína y su mensaje feminista. Gloria Steinem, fundadora y directora de la revista $M s .{ }^{27}$, denunció públicamente el maltrato que la superheroína estaba sufriendo. Steinem se consideraba a sí misma una feminista de segunda generación (Sandifer 2013: 116), la continuación directa de las primeras conquistas obtenidas por las sufragistas. En 1972, su publicación destacó a la heroína como portada, subrayando un potencial del que se había alejado.

\footnotetext{
${ }^{25}$ Por ejemplo, existió una fase marcada por las pujantes artes marciales en los cómics de Wonder Woman (Sandifer 2013: 102-115) y donde Diana se aleja por completo de sus raíces mitológicas (Darowski 2014). Con todo, el marco donde más recortes se hicieron fue en la sexualidad de la amazona. Siguiendo las teorías de Wertham, Wonder Woman era acusada de dar un mensaje confuso y con guiños lésbicos nefastos para las nuevas generaciones. Pasarían décadas para que la protagonista recuperase la libertad en ese terreno que planteó el círculo de Marston y sus colabores/as.

${ }^{26}$ Protagonizada por la antigua miss Mundo, Lynda Carter, el show se mantuvo durante tres temporadas. Los constantes recortes presupuestarios lastraron las tramas del programa, aunque alcanzó una notable popularidad. Por ejemplo, en España apenas se conocía a la heroína hasta la década de los 70, puesto que los lectores/as en el país solamente podían acceder a sus cómics a través de editoriales mexicanas y argentinas.

${ }^{27}$ La socia de Steinem en dicha empresa fue la activista Dorothy Pitman Hughes.
} 


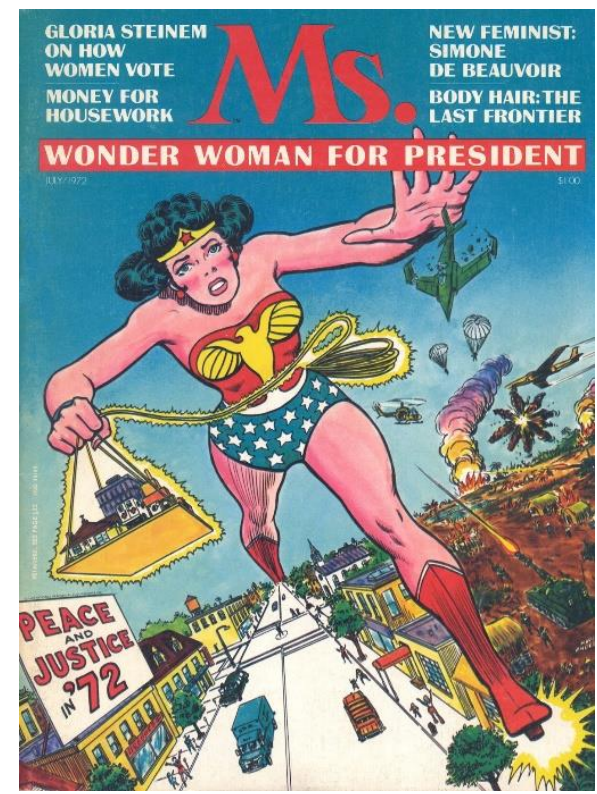

Fig. I. Portada revista Ms. con Wonder Woman (julio 1972)

La revista se consideraba heredera del nuevo movimiento de liberación femenino (Morgan 1973) y trabajos como La mística de la feminidad ${ }^{28}$. Eran años difíciles y de contraste de opiniones, aquella nueva generación de activistas encontraría oposiciones como la planteada por Phyllis Schlafly, líder de la facción conservadora contraria a las peticiones de enmiendas en la constitución norteamericana para garantizar la igualdad de sexos (McCausland 2017: 106-107).

Con su elección para la portada de la revista $M s$., Steinem volvía a colocar a la princesa amazona en su lugar original en esta causa. Se incluyó para la ocasión un artículo de Joanne Edgar sobre el declive de las superheroínas tras la prometedora década de los cuarenta. Si bien quedaba un largo camino por recorrer, aquel ejemplar de Ms. colocaba al icono de la historieta como objeto de debate (Matsuuchi 2012: 118142). La oportunidad de recuperar aquella esencia llegó en 1980, ocupando la

\footnotetext{
${ }^{28}$ Este libro, objeto de múltiples reediciones desde 1963 habría sido escrito por Betty Friedan, quien cuestionaba el papel que la sociedad estaba obligando la sociedad a ejercer a las mujeres en los hogares (Friedan 2017).
} 
presidencia de DC Comics Jenette Kahn, quien pensaba hacer partícipe a Wonder Woman del nuevo universo de ficción actualizada que iba a plantear la editorial.

El camino para devolverle a Diana una colección propia y de importancia quedó abierto en 1985, con la salida al mercado de la mini-serie Crisis en Tierras Infinitas, un macro-evento entre colecciones que dio como resultado la simplificación de las distintas realidades alternativas que sufrían algunos de los personajes más emblemáticos de DC. Es decir, los nuevos equipos creativos tendrían libertad para partir de cero desde ahí, sin las ataduras de décadas de historias, no pocas veces incluso incompatibles entre sí.

Janice Race, editora de la colección de la guerrera amazona, terminó aceptando la petición de George Pérez, uno de los dibujantes más reputados de la compañía, quien tenía novedosas ideas para actualizar a Diana. Fruto de una estrecha colaboración con el guionista Len Wein y, especialmente, la editora y escritora Karen Berger (Hernando 2004: 114-130), Pérez se convenció de que la mitología clásica podría servir para reformular el discurso feminista a finales del siglo XX.

El relanzamiento de Wonder Woman en 1987 permitió conocer más cosas sobre Isla Paraíso; por primera vez, se daba el nombre de su capital: Temiscira. Siguiendo una idea del guionista Greg Potter, las amazonas que allí residían eran reencarnaciones de todas aquellas mujeres que habían sido asesinadas violentamente en el mundo del ser humano (Monje 2017: 41-52).

Ni siquiera en la etapa de Marston y Peter se había profundizado en el panteón olímpico con el nivel de detalle que se haría en esta fase. Aquí se revelaría que el nacimiento de la heroína habría sido un regalo de los dioses a la reina Hipólita, siendo Diana modelada desde la arcilla, en un claro guiño a las leyendas mitológicas. 
Uno de los mitos sería de capital importancia para comprender la actitud de las amazonas con respecto al resto del mundo. Pérez aporta su propia versión sobre el noveno de los doce trabajos llevados a cabo por Hércules, el robo del cinturón de Hipólita (Hard 2004: 346-348). En esta visión, la reina amazona se vería traicionada en su confianza por el hijo bastardo de Zeus, cuya soldadesca, además, esclavizaría a las habitantes de la isla. Fruto de aquella afrenta, tras liberarse del yugo, todas ellas jurarían no volver a someterse a la autoridad de ningún poder externo.

Diana, por ende, sería la única isleña que no vivió en primera persona esa tragedia, lo cual la hará tener un fuerte deseo de salir exterior y menor desconfianza ante el sexo contrario. Pérez también revisita la figura de Ares (Hard 2004: 229-231), convertido en el urdidor de las maquinaciones que culminan con Steve Trevor aterrizando, de nuevo, en Temiscira por un accidente aéreo. La deidad de la guerra adquiere aquí un nivel de amenaza sin precedentes en la colección, pues su fortaleza emana del culto a la violencia que todavía brindan los seres humanos, lo cual convierte su duelo con Wonder Woman en una misión prácticamente imposible ${ }^{29}$.

Patty Kenkins y su equipo beben directamente de esta etapa del personaje, incluyendo que, lógicamente, la lengua materna de Diana sea el griego clásico, aunque la heroína es capaz de aprender con gran facilidad otros idiomas. Siguiendo la fórmula de leyendas como la de Pentesilea (Kleist 1978), se presenta una sociedad de guerreras que buscan la paz, una civilización que combina los avances tecnológicos con una especie de Arcadia atemporal. El rediseño de George Pérez volvió a dar un sello distintivo a Wonder Woman con respecto a cualquier otro personaje del universo DC.

\footnotetext{
${ }^{29}$ La película de 2017 se nutre fundamentalmente del Ares de Pérez, aunque con alguna licencia. En el cómic original, Diana es capaz de vencer una batalla imposible mediante la persuasión, convenciendo al propio Ares de que si fructificaran sus planes se quedaría sin adoradores. Probablemente, fruto de las convenciones del blockbuster, el film termina optando por una batalla más convencional entre ambos.
} 
El elenco de secundarios también se vería beneficiado por el tratamiento que le dio el nuevo autor de la serie. Por ejemplo, Etta Candy, antigua amiga de Diana en la etapa clásica (Lepore 2014: 17) y mera comparsa cómica tras la etapa de Marston en la colección. Convertida ahora en oficial de inteligencia del ejército, se iría alejando de sus últimos años como pausa humorística de las aventuras de su compañera, además de añadirse el giro argumental de que ahora será ella quien tenga una relación sentimental con Steve Trevor ${ }^{30}$, lo cual permitiría a Pérez dejar a Diana sin pareja romántica para otorgarle una mayor libertad en este reinicio (Monje 2017: 43).

El juego propuesto en estas sagas parte del acento heteropatriarcal de la antigua mitología para reconfigurarlas a través de la protagonista. En esos años, Diana sería capaz de resistir los lujuriosos deseos del mismísimo Zeus, el soberano absoluto de la tercera generación de olímpicos, célebre por sus numerosas infidelidades a su esposa Hera (Hard 2004: 121-128).

Mención especial merecería “Time Passages", la historia favorita del propio Pérez, donde a través de los ojos de cuatro mujeres de diferente extracción social se analiza el impacto que una figura como Wonder Woman tendría en la sociedad (Hernando 2004: 120-130). Cada una de ellas aporta una perspectiva distinta pero complementaria para entender mejor a la amazona.

La satisfacción de Pérez a la cabecera de la colección cambiaría con la ejecución de Guerra de los dioses, ambiciosa saga para conmemorar el 50 aniversario de la amazona en DC Comics. Sin embargo, los problemas para llevar a buen puerto el

\footnotetext{
${ }^{30}$ Para la película se opta por una solución intermedia. Resulta evidente que Diana (Gal Gadot) y Trevor (Chris Pine) sienten una mutua fascinación desde que se conocen, si bien la urgencia de la misión impide que ese interés les permita ahondar en ese vínculo que podrían crear. "Nos ha faltado tiempo", llega a decirle Diana al piloto en la última escena entre ambos. Se trata de un romance bien llevado y que no cae en convencionalismos, fiel al espíritu de la etapa de Marston, que además coloca en plano de igualdad a los dos posibles amantes.
} 
crossover $^{31}$ terminarían con la salida de la editorial de quien, con la excepción del primer equipo creativo de Marston, más había hecho por devolver a la heroína a sus verdaderas raíces.

\section{La embajadora}

Admirador del trabajo llevado a cabo por su predecesor, William Messner-Loebs decidió alejarse de los principales puntos que habían hecho célebre el nuevo título de la amazona, evitando caer en comparaciones. Así, llevaría a la protagonista a combatir el crimen de los bajos fondos de Boston $^{32}$, alejándose del tono mitológico de Pérez. Asimismo, escribió varios números de aventuras en el espacio que se enmarcaban con más facilidad en el campo de la ciencia ficción que en la reivindicación social.

Aunque hay variaciones gráficas de relevancia ${ }^{33}$, los primeros compases de Loebs en la andadura de Wonder Woman no modifican en exceso la tarea llevada a cabo por Pérez en su tratamiento la princesa guerrera; eso sí, hay un punto de inflexión en el mes de septiembre de 1994, cuando el guionista introduce a Artemisa, líder destacada de la

\footnotetext{
${ }^{31}$ Forma de referirse en el cómic a la interrelación durante unos números de protagonistas de series diferentes. La industria norteamericana suele emplearlos por la capacidad que tiene de atraer al público, especialmente para beneficiar a aquellos personajes que en ese momento sean menos populares. Guerra de dioses se desarrolló durante el año de 1991, ante reiteradas quejas de Pérez por la poca publicidad que la compañía dio al evento en comparativa con los esfuerzos realizados en aniversarios de otros iconos de DC como, por ejemplo, Superman. A pesar de los ambiciosos objetivos de colocar a Diana en el ojo del huracán de una guerra de los olímpicos por las confabulaciones de Circe, la saga no alcanzó el beneplácito de crítica y público, los cuales la juzgaron poco coordinada e incapaz de explotar su verdadero potencial.

${ }^{32}$ Ideal original de Greg Potter, originario de Boston, quien quiso colocar a la amazona en su ciudad natal, a diferencia de la mayoría de héroes DC que vivían en ciudades ficticias (Gotham, Metrópolis, etc.). ${ }^{33}$ Las portadas de aquel período, efectuadas por el artista británico Brian Bolland, marcarán un importante cambio de apariencia en Wonder Woman. La más reseñable de las modificaciones es relativa al uniforme. Cuando Diana pierda su título de primer inter pares en la comunidad amazona, adoptará una indumentaria más propia de la década de los noventa del pasado siglo. Chaqueta azul sobre mallas cortas y un aspecto más agresivo. El dibujante brasileño Mike Deodato Junior seguiría el estilo de Bolland, aunque las modificaciones también recibieron acusaciones de un sector del público por sexualizar más al personaje y hacer que perdiera las señas de identidad de su civilización (Monje 2017: 44).
} 
tribu de los Bana-Mighdall. Dichas guerreras serían fruto de una escisión contraria al liderazgo de Hipólita, justo después de la caída de Temiscira ante las huestes de Hércules, las cuales eligieron como nueva reina a Antiope, tía materna de Diana, con la que se exiliaron a Egipto.

Las habilidades marciales de Artemisa rivalizan con las de la propia heroína, hasta el punto de llegar a poder batirla en competición y arrebatarle el título de Wonder Woman durante un breve espacio de tiempo. El filme de Patty Jenkins transmite esa competitividad lacedemonia en la figura de Antíope (Robin Wright). Si bien breve, la aparición de una actriz de la fortaleza de Wright da un gran significado a la hermana de Hipólita, quedando claro que ella juega el papel más destacado a la hora de motivar a su sobrina a alcanzar la perfección en el campo de batalla. Reconocida como la mejor combatiente de la isla, su muerte será el catalizador que convencerá a Diana de que debe ir al mundo de los seres humanos.

De cualquier modo, los objetivos de Artemisa serán sobre todo funcionales en el arco argumental orquestado por Messner-Loebs. Su triunfo se revelaría como un ardid de la reina Hipólita, quien, preocupada por una profecía que alude a la muerte de la mejor guerrera de las amazonas, urde la competición para que su hija pierda el título. Se trataría del tipo de augurio de equívocos que tanto se daban en el antiguo oráculo griego de Delfos (Scott 2015).

Generalmente no tan reconocida por la crítica, esta etapa de Messner-Loebs como escritor de Wonder Woman tiene el mérito de plantear tensiones internas en la comunidad de las amazonas, especialmente en el cuestionamiento de la autoridad de Hipólita y su cerrazón hacia el mundo exterior (Monje 2017: 44). 
Tras la marcha de Messner-Loebs, Wonder Woman sufrirá un desfile de guionistas y dibujantes que mantendrán a la serie en unos niveles muy convencionales ${ }^{34}$. Al fin encontramos un punto de inflexión en 2008, cuando Gail Simone se convierte en la primera guionista de la colección ${ }^{35}$. A lo largo de una treintena de números, Simone logra captar la atención del público con una revitalización del personaje, incluyendo una colaboración con el mismo George Pérez con motivo del número seiscientos de la amazona $^{36}$. Si, por ejemplo, en el film de Patty Jenkins se muestra una gran lealtad de las súbditas de Hipólita, la guionista introduce los resultados de una conjura urdida por algunas amazonas de la guardia personal de la reina.

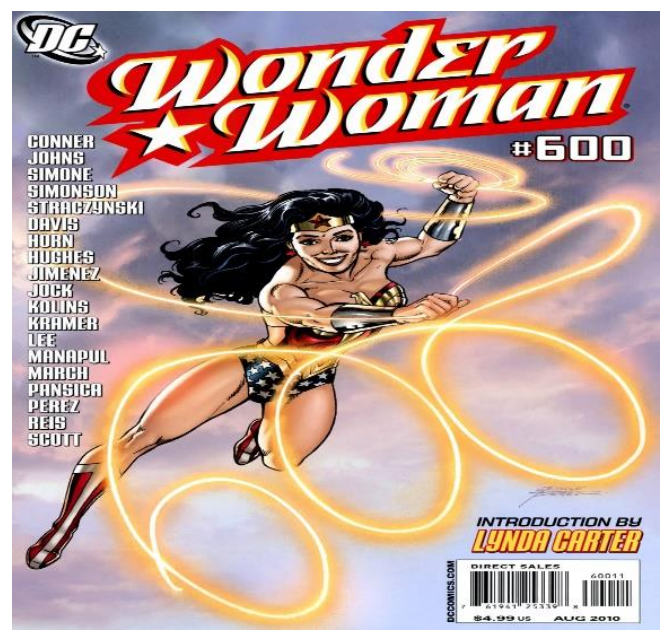

Fig. II. Portada del número 600 de Wonder Woman (agosto 2010)

\footnotetext{
${ }^{34} \mathrm{La}$ única excepción sería el autor canadiense John Byrne. A pesar de su historial de éxitos con personajes adscritos a la ciencia ficción (Los Cuatro Fantásticos, La Patrulla X, Superman, etc.), no logró trasladar su habilidad como guionista al campo más mitológico de Wonder Woman. No solamente se ignoran sagas anteriores, sino que Diana se aleja notablemente de cualquier clase de reivindicación feminista. Una excepción a comienzos del nuevo milenio sería el escritor Alan Heinberg, quien posteriormente redactaría junto a Geoff Johns el primer borrador del guión de Wonder Woman para Warner Bros.

35 Nos referimos, evidentemente, al reconocimiento en los títulos de crédito. Como hemos visto en epígrafes anteriores, Olivia Byrne, Elizabeth Holloway o Karen Berger, entre otras, tuvieron un papel decisivo en algunos de los rasgos fundamentales de la heroína.

${ }^{36}$ Simone homenajearía los años de la Edad Dorada de Diana con la saga El Círculo, además de jugar con la guerra entre diferentes panteones de deidades (egipcias, griegas, nórdicas...).
} 
La estela de Simone será seguida por Greg Rucka, cuya primera etapa en la serie, entre 2002 y 2005, permitiría explorar nuevas facetas de la heroína (Sandifer 2013: 214228). El guionista colocaría a Diana una como líder de la embajada que Temiscira decide instalar para mejorar sus relaciones con las naciones del planeta.

Rucka hará a Wonder Woman publicar una autobiografía que recibirá diferentes niveles de aceptación por parte del público. Explorando el subtexto que ya estaba en Marston, queda clara la bisexualidad de la protagonista y su defensa de la libertad en ese terreno (Lepore 2014: 143-149). Tampoco se olvida de su herencia en la tradición helenística, con el álbum Hiketeia ${ }^{37}$.

Otro nombre a destacar será el de Brian Azzarello, quien llegará en septiembre de 2011 al título para dar uno de los giros argumentales todavía no explorados con anterioridad. Durante décadas, Wonder Woman había hecho frente a dioses del calibre de Ares o el mismísimo Zeus. Sin embargo, el escritor plantea una situación donde el trono del padre de los olímpicos está vacante, siendo la gran oportunidad de Hera para obtenerlo. La poderosa diosa procurará vengar viejas afrentas a cualquier coste, incluyendo a las propias amazonas.

\footnotetext{
${ }^{37}$ Complejo ritual en la antigua Grecia por el que una persona acepta responsabilidades de magisterio y protección con respecto a otra. Danielle Wellys logrará recibir los beneficios de ese juramento cuando sea aceptada por Diana como pupila. En defensa de la chica con un turbulento pasado, Wonder Woman será capaz de desafiar a otro de los iconos de DC, Batman.
} 


\section{Conclusión}

Con una película exitosa en taquilla en $\operatorname{su} \operatorname{haber}^{38}$ y una nueva hornada de autoras dispuestas a aportar su visión sobre Wonder $\operatorname{Woman}^{39}$, la popularidad a nivel global de la heroína nunca ha sido más alta. La confirmación de la participación de escritores como Grant Morrison, reconocido admirador de los trabajos de Marston, o el retorno de Rucka al universo Rebirth de DC garantizan un tratamiento adecuado de este icono de las historietas. No obstante, la propia historia de un personaje con más de 75 años de existencia impresa nos recuerda los riesgos y la facilidad con la que se puede caer en una banalización en aras de satisfacer los rigores del mercado.

A diferencia de muchas otras colegas de industria, Wonder Woman no surgió encorsetada desde una discriminación sexista para irse abriendo camino con el transcurrir de los avances sociales. Desde su propio punto de partida, Marston, Byrne, Holloway y Peter le otorgaron un papel protagonista, con una clara conciencia feminista, personificando en las viñetas la representación idealizada del nuevo tipo de mujer que iba a reclamar el reconocimiento a su valía social y profesional.

La oportunidad en la coyuntura actual se antoja única. Reducida por la censura más conservadora a una caricatura de su verdadero potencial a mediados del siglo $\mathrm{XX}$, durante mucho tiempo se consideró a dicha heroína como un hermoso pin-up sin

\footnotetext{
${ }^{38}$ Previamente encontramos el telefilm protagonizado por Cathy Lee Crosby, estrenado por la cadena ABC el 12 de marzo de 1974. Bajo la dirección de John D. F. Black, la película tiene poco que ver con la esencia del personaje, siendo más bien una cinta adscrita al género de espías y misiones especiales.

${ }^{39}$ Destaca a ese respecto la reciente aparición de La Verdadera Amazona, entera responsabilidad de la artista Jill Thompson. Pintado en acuarela, la novela gráfica explora con una nueva óptica los primeros años de la princesa de Isla Paraíso. Consentida por todas las amazonas como una gracia concedida por el Olimpo a la reina Hipólita, Diana va malcriándose y adoptando una posición de sumo egoísmo. La manera de narrar la toma de conciencia de responsabilidad de la futura Wonder Woman ha valido dos premios Eisner a este trabajo (Monje 2017: 41).
} 
ninguna profundidad, indiferenciada y sin ninguna característica inspiradora. Ahora dispone de un bagaje de etapas complejas que la abordan desde múltiples perspectivas (guerrera, embajadora, defensora por la lucha de la igualdad, etc.) y la alejan de simplificaciones anteriores.

Por último, siguiendo la senda iniciada por Karen Berger y George Pérez, el trasfondo de Cultura Clásica y mítico que rodea Temiscira se presenta como un filón todavía repleto de opciones para enriquecer el universo de Diana en cualquiera de sus adaptaciones. La posibilidad de que una protagonista con este alcance para el gran público pueda servir para re-interpretar desde una óptica femenina ese contexto mítico, tradicionalmente con marcado acento patriarcal, permitiría seguir el camino trazado por el equipo creativo original de Wonder Woman.

\section{Referencias bibliográficas}

Darowski, Joseph (ed.). 2014. The Ages of Wonder Woman: Essays on the Amazon Princess in changing times. North Carolina: McFarland \& Company.

Douglas, Susan. 1994. The rise of enlightened sexism: How Pop Culture Took Us from Girl Power to Girls Gone Wild. New York: St. Martin's Griffin.

Friedan, Betty. 2017. La mística de la feminidad (Feminismos). Madrid: Cátedra.

Greenberger, Robert. 2017. Wonder Woman: Amazona. Heroína. Icono. Barcelona: ECC Ediciones.

Hanley, Tim. 2014. Wonder Woman unbound: the curious history of the world's most famous heroine. Chicago: Chicago Review Press.

2016. Investigating Lois Lane: The turbulent history of the Daily Planet's ace reporter. Chicago: Chicago Review Press.

Hard, Robin. 2004. El gran libro de la mitología griega. Madrid: La Esfera de los Libros. 
Hernando, David. 2004. En primera persona: George Pérez. Palma de Mallorca: Editorial Dolmen.

Kleist, Heinrich. 1978. Pentesilea: tragedia. Madrid: Editorial Magisterio Español.

Langley, Travis and Mara Wood. 2017. Wonder Woman Psychology: Lassoing the Truth. New York: Sterling Publishin Company.

Lepore, Jill. 2014. The secret history of Wonder Woman. Londres: Scribe Publications.

Matsuuchi, Ann. "Wonder Woman Wears Pants: Wonder Woman, Feminism and the 1972 Women's Lib Issue”. Colloquy, 24: 118-142.

McCausland, Elisa. 2017. Wonder Woman: El feminismo como superpoder. Madrid: Errata naturae.

Mitchell Peters, Brian. 2003. "Qu(e)erying Comic Book Culture and Representation of Sexuality in Wonder Woman". CLCWeb: Comparative Literature and Culture, 5 (3): $1-9$.

Monje, Pedro. 2017. "Wonder Woman 1". Dolmen: Revista de información sobre cómic, 263: 37-44.

. 2017. "Wonder Woman 2". Dolmen: Revista de información sobre cómic. 264: 41-52.

2017. "Wonder Woman 3". Dolmen: Revista de información sobre cómic, 265: 33-42.

Morgan, Robin (ed.). 1973. Sisterhood is Powerful: An Anthology of Writings from the Women's Liberation Movement. New York: Random House.

Moulton Marston, William. 1928. Emotions of Normal People. Londres: Kegan Paul, Trench, Trubner \& Co. Ltd.

Nicholson, Hope. 2017. The spectacular sisterhood of Superwomen: awesome female characters from comic book history. Philadelphia: Quirk Books.

Pujol Tost, Laia. 2009. "Safo de Lesbos: la décima musa griega". Clío: Revista de historia, 97: 38-49.

Reed, Miriam. 2003. Margaret Sanger: Her Life in Her Words. New Jersey: Barricade Books.

Robbins, Trina. 1997. The Great Women Superheroes. Northampton: Kitchen Sink Press.

Robinson, Lilian. 2004. Wonder Women: Feminisms and Superheroes. New York: Routledge.

Rodríguez, José Joaquín. 2013. King Kirby: Jack Kirby y el mundo del cómic. Palma de Mallorca: Editorial Dolmen. 
Sandifer, Philip. 2013. A Golden Thread: An unofficial history of Wonder Woman. Wroclaw: Eruditorum Press.

Scott, Michael. 2015. Delfos: Historia del centro del mundo antiguo. Barcelona: Ariel.

Unwin, Melanie. 2008. "The 1908 pankhurst medal remembering the campaign for votes for women in Parliament". Parliamentary history, 27 (3): 436-443. 